УДК 37.04-053

DOI: $10.24045 /$ ap.2017.1.10

МОДЕЛИРОВАНИЕ КАК МЕТОД ФОРМИРОВАНИЯ ПРЕДСТАВЛЕНИЙ О ВРЕМЕНИ У ДЕТЕЙ СТАРШЕГО ДОШКОЛЬНОГО ВОЗРАСТА

3. А. Ломако
Кандидат педагогических наук, дочент Государственный сочиальногуманитарный университет

2. Коломна, Московская область, Россия

\title{
MODELING AS A METHOD OF FORMING NOTIONS OF TIME IN CHILDREN OF SENIOR PRESCHOOL AGE
}

\author{
Z. A. Lomako
}

\author{
Candidate of Pedagogical Sciences \\ assistant professor \\ State Social Humanities University \\ Kolomna, Moscow region, Russia
}

\begin{abstract}
The need to navigate in time is a vital necessity of modern man and to develop children's understanding of time is necessary already in preschool age, to create a basis for the development of the qualities are necessary for the child while studying in school and doingdaily life. The question that is directly sensory basis for the perception of time, for a long time were solved by psychologists and physiologists. In a number of studies have shown that daily cyclical rhythm of human life is dependent on illumination changes, it was found that not all processes are of endogenous nature, a set of external reasons, for example, movements of Earth, Sun and moon. We hypothesized that the use of the method of modeling in the learning process will improve the efficiency of formation of temporal concepts in children of preschool age.
\end{abstract}

Keywords: modeling; preschoolers; perceptions of time; geo-physical conditions; educational process; structure of sign-symbolic activities.

С проблемой времени человек сталкивается постоянно. Он живет во времени. Современная жизнь характеризуется острой нехваткой времени, быстрым темпом жизни. Чтобы быть успешным, человеку необходимо хорошо ориентироваться во времени, распределять время, чувствовать его, анализировать, насколько рационально оно было использовано, ценить время. Современная жизнь требует от челове- ка высокой культуры временных представлений, быстрой реакции на время, гибкости перестройки своего поведения и деятельности в зависимости от жизненных условий.

Необходимость ориентироваться во времени является жизненной необходимостью современного человека. Именно поэтому необходимо формировать у детей представления о времени уже в дошкольном возрасте. Элементарные представ- 
ления о времени могут быть сформированы уже в младшем дошкольном возрасте. Особое значение данная проблема имеет в старшем дошкольном возрасте в связи с предстоящим обучением в школе. Время становится для ребенка регулятором его деятельности. Он сам должен ориентироваться в отрезках времени различной протяженности, менять темп, ритм действий. Умение регулировать и планировать деятельность во времени создает основу для развития таких качеств личности, как организованность, собранность, целенаправленность, точность, необходимых ребенку при обучении в школе и в повседневной жизни.

Формирование представлений о времени у детей является сложной проблемой. Эта сложность обусловлена тем, что время как категория, обладает рядом особенностей, которые делают его абстрактным понятием. Время нельзя потрогать, увидеть, попробовать на вкус, не имеет наглядных форм. У детей старшего дошкольного возраста основным видом мышления является наглядно-образное мышление и только начинают складываться зачатки логического. Эта психологическая особенность старших дошкольников усложняет процесс формирования представлений о времени. Таким образом, с одной стороны, в старшем дошкольном возрасте необходимо формировать представления о времени, с другой стороны, этот процесс усложнен возрастными особенностями детей.
В нашем случае усложнение усугублялось тем, что исследование проводилось в комплексе «детский сад - школа» за полярным кругом. В эксперименте в период с сентября 2010 г. по май 2011 г. участвовало 10 детей в возрасте 5-6,5 лет, дети старшего дошкольного возраста. Длительность полярной ночи и скудность растительного мира окружающей природы затрудняли процесс формирования представлений о времени рекомендуемыми программами воспитания и обучения дошкольников. Жилая часть местности постоянно освещалась прожекторами, а рядом с детским садом располагался птичник, где режим дня и ночи регулировался для птиц особыми прожекторами, имитирующими освещенность солнца центральных районов страны.

В связи с большим объемом познавательного материала, заложенного в современных программах воспитания и обучения дошкольников, все более актуальным становится выбор методов обучения детей $[2 ; 4]$. В нашем исследовании знания становились не целью, а средством развития ребенка. Старший дошкольный возраст - это возраст образных форм сознания, и основными средствами, которыми овладевает ребенок в этом возрасте, являются образные средства: сенсорные эталоны, различные символы, знаки, наглядные модели. Социальный опыт детей требовал совершенствования. И накапливался этот опыт при помощи взрослых, под их руководством. 
Мы предположили, что использование метода моделирования в процессе обучения позволит повысить эффективность формирования временных представлений у детей старшего дошкольного возраста.

Термины «модель», «моделирование» очень распространены в научной литературе. Теоретический анализ психолого-педагогической литературы показал, что моделирование может рассматриваться с разных позиций. В одних работах моделирование выступает как общая интеллектуальная способность (Л. А. Венгер, Р. И. Говорова, Л. И. Цеханская и др.), В. В. Давыдовым, Д. Б. Элькониным моделирование рассматривается как действие, одно из учебных действий, входящих в состав учебной деятельности, в работах Н. Г. Салминой как деятельность, входящая в структуру знаково-символической деятельности.

Как показывают результаты исследований, выполненных под руководством Н. Г. Салминой, моделирование может представлять собой самостоятельную деятельность, и, следовательно, требует специального формирования, должно становиться объектом обучения [6]. Моделирование трактуется как вид знаково-символической деятельности наряду с замещением, кодированием и схематизацией. Именно моделирование является наиболее сложными развитым видом знаковосимволической деятельности. Мы придерживаемся точки зрения Н. Г. Салминой.

Моделирование - знаковосимволическая деятельность, за- ключающаяся в получении объективно новой информации (познавательная функция) за счет оперирования знаково-символическими средствами, в которых представлены структурные, функциональные, генетические связи (на уровне сущности) [6, с. 83].

Из сказанного делаем вывод, под моделированием понимают как метод исследования объектов на их моделях, так и сам процесс построения и изучения моделей. При этом моделирование в обучении имеет два аспекта - моделирование как содержание, которое учащиеся должны усвоить и как средство, без которого невозможно обучение. В качестве средств моделирования нами рассматривается модель (с точки зрения моделирования как метода обучения) и моделирующие действия (с точки зрения моделирования как деятельности).

Для наших детей, приобретающих социальный опыт в специфических условиях, ценным было то, что моделирование своим объектом имеет модели. Самая основная характеристика модели - то, что она является заместителем реальности, дети работают на моделях, а не в реальности. В структуре моделирования как деятельности, конечно, сложной деятельности, можно выделить такие составляющие ее операции, как предварительный анализ, перевод реальности или текста, ее описывающего, на знаковосимволический язык, работа с моделью, соотнесение результатов, полученных на модели, с реальностью.

В. В. Давыдов и А. У. Варданян отмечают особенности учебных мо- 
делей: учебные модели имеют знаковый и образный характер; учебные модели оперативны, т. е. содержат определённые элементы (чёрточки, квадратики, стрелки), которые указывают на способ работы с материалом; они эвристичны, т. е. работа с ними позволяет получить новое знание, которое трудно приобрести при исследовании реального объекта [3].

Основной функцией учебных моделей, по мнению Н. Г. Салминой, является функция получения новых знаний при оперировании моделями, которая реализуется посредством указанных ниже конкретных функций: функция построения так называемой «идеализированной предметности» - особой реальности, в которой выражены и воссозданы существенные черты изучаемого явления, что создаёт дополнительную возможность их исследования; функция абстрагирования свойств, которые являются предметом изучения, их фиксация в модели, что позволяет исследовать свойства в чистом, «незашумленном», отделённом от несущественных черт виде. Именно благодаря этой функции модель является очень эффективным средством обучения, ускоряющим усвоение знаний и обеспечивающим их обобщённость; функция целостного («симультанного») восприятия компонентов, включённых в структуру явления, что часто помогает найти идею решения задачи; функция оперирования знаниями, особенно для моделей, выраженных в буквенно-цифровой форме [6, с. 96].
По-разному подходят исследователи и к проблеме классификации учебных моделей. В общем виде большинство классификаций моделей по форме выделяют материальные (т. е. существующие реально) и идеальные (т.е. мысленные, умозрительные) модели.

К материальным относят все те модели, что сконструированы человеком искусственно из каких-либо вещественных предметов или взяты из природы в качестве образцов. Такие модели могут отображать пространственные особенности объектов, воспроизводить ряд физических параметров оригинала или его структурные свойства, имитировать один процесс с помощью других и т. д. Материальные модели обычно делят на статические и динамические. Функционируют они как любой материальный объект по объективным законам природы и допускают определенные предметные преобразования.

В нашем исследовании мы взяли за основу классификацию Н. Г. Салминой, согласно которой все модели подразделяются на две группы:

1. Модели, пространственнографические, отражающие структуру изучаемых объектов и отношений (макеты, чертежи, диаграммы и Т. п.)

2. Модели, в буквенноцифровом виде выражающие изучаемые связи (математические выражения, равенства, уравнения, формулы и т. п.) [6, с. 97].

Пространственно-графические модели предполагают прежде всего 
«пространственное моделирование непосредственных отношений, графическое моделирование сущности». Структура изучаемого явления, связи его элементов часто не видны дошкольникам в исходном эмпирическом материале. Исследуемая структура может не просматриваться ребёнком и за записями, выраженными в буквенно-цифровой форме. Выявление сущности изучаемого материала продуктивнее осуществляется при работе с пространственно-графическими моделями. Применение графических построений в обучении не всегда результативно по ряду причин: нет чёткого, фиксированного алфавита графического языка; элементы его не определены и часто строятся произвольно; нет фиксированных правил соединения элементов между собой (синтаксиса); часто они создаются в данном педагогическом контексте для определённого, специфичного материала; нет общего принципа выбора графических средств (диаграммы, чертежи, иллюстрации, графики) для конкретных ситуаций; нет единых правил преобразования графических моделей, при которых сохранялся бы инвариант; кроме того, оперирование графическими моделями требует определённого уровня развития пространственного мышления. Поэтому построение и декодирование графических моделей без специального обучения может оказаться трудным для учащихся.

Пространственно-графические модели, в свою очередь, подразделяются на подвижные и неподвижные. Подвижные модели представ- ляют собой символы (в виде геометрических фигур, палочек, полосок и т. п.), которыми ребёнок может манипулировать, т.е. свободно «передвигать рукой»: например, строить модели задачной ситуации из палочек или кружков.

Неподвижные пространственнографические модели представляют собой изображения символов (отрезков, геометрических фигур, стрелок и т. п.) на листе бумаги.

Буквенно-цифровые модели имеют фиксированный алфавит, правила обращения с алфавитом (синтаксис), правила перевода и оперирования. Тем не менее у них свои трудности: нужно держать в уме весь алфавит, значение каждого символа, и с каждой новой темой этот алфавит расширяется; оперирование буквенно-цифровыми моделями может привести к формализму в приобретении новых знаний, к непониманию сути производимых преобразований.

Средства обучения являются важным компонентом в организации учебного процесса в дошкольном учреждении. Средство обучения это идеальный или материальный объект, который используется для освоения знаний, формирования опыта, познавательной и практической деятельности.

Идеальные средства обучения это те усвоенные ранее знания и умения, которые используют взрослые и дети для усвоения новых знаний. Материальные средства обучения - это физические объекты, которые используют педагог и обучающийся для детализированного обучения. 
Итак, средствами обучения являются все те материалы, с помощью которых педагог осуществляет обучающее воздействие.

Речь как средство обучения многоаспектна: она отражает уровень умственного развития говорящего, опосредует процессы восприятия, воздействует и управляет, обеспечивает познание и общение, выражает отношение и позицию личности к информации и слушателям. В процессе овладения лингвистическими средствами речь педагога является образцом для дошкольников, она не только средство изложения информации, но и средство управления вниманием, средство образования представлений и понятий.

Н. Г. Салмина. в своих работах подробно рассматривает средства материализации и даёт своё определение материализации [6]. Термин «материализация», который широко употребляется в литературе, особенно в теории поэтапного формирования умственный действий, определяется как фиксация идеального внешними средствами, как создание так называемых «идеализированных» объектов. Материализация, по её мнению, выступает и как процесс, и как результат. Она предполагает не только воплощение идеального внешними средствами, но и саму деятельность построения и использования идеализированных объектов, их преобразование, в процессе которого происходит выделение существенного. Таким образом, материализация включает не только объективированный продукт, но и сам процесс объективи- зации, а также использование внешних средств деятельности.

Назначение и суть материализации - обеспечение специфического действия, обнажающего, выделяющего сущность явления, его закономерности.

Существует три вида средств материализации: знаковосимволические средства; схематизированные средства; знаковые средства.

Средства наглядности и материализации одни и те же, а именно конкретные предметы, схемы, модели, определённое расположение материала с использованием цвета, подчёркивания и др., дающее возможность выделить существенное. Если материализация обеспечивает выделение существенного в действие, то наглядность - это свойство средств материализации обеспечивать выделение существенного в плане восприятия. Но «наглядность» отличается от термина «материализация», хотя и связана с ним. Если материализация обеспечивает выделение существенного в действие, то наглядность - это свойство средств материализации обеспечивать выделение существенного в плане восприятия.

Практическая работа проводилась с детьми 5-6,5 лет, с детьми старшего дошкольного возраста. Мы предлагали детям задания, изложенные в тетрадях Н. Г. Салминой, так как они позволяли расширять представления детей об окружающем мире других регионов страны, где есть чёткая смена дня и ночи, времён года, характерных 
признаках этих отрезков времени. Любознательность детей постоянно была направлена на познание окружающего мира и построение своей картины этого мира. Дошкольники, играя, экспериментируя, пытались установить причинно-следственные связи и зависимости. У детей возникало множество вопросов по поводу явлений окружающей жизни. Чем активнее в умственном отношении ребенок, тем больше он задавал вопросов и тем разнообразнее были эти вопросы. При возникновении перед ними некоторых задач они пытались решить их, реально примеряясь и пробуя, они могли решать задачи в уме. Дети представляли себе реальную ситуацию и как бы действовали в ней в своем воображении. Такое мышление, в котором решение задачи происходят в результате внутренних действий с образами, называется нагляднообразным. Образное мышление основной вид мышления старшего дошкольника. Он, конечно, может в отдельных случаях мыслить логически, но следует помнить, что этот возраст сензитивен к обучению, опирающемуся на наглядность.

Изменения в мышлении дошкольника прежде всего связаны с тем, что устанавливаются все более тесные взаимосвязи мышления с $p e-$ чью. На вопросы дети отвечали достаточно точными, краткими или же развернутыми (если это было необходимо) ответами, оценивали высказывания и ответы сверстников, дополняли или исправляли их. Активно пользовались временными наречиями, но не все временные категории осознавались ими и пра- вильно отражались в речи. Дошкольники выполняли действия по словесной инструкции, усвоение знаний происходило на основе объяснений, но только при опоре на чёткие наглядные представления.

Элементы учебной деятельности проявлялись в умении дошкольников слышать и слушать взрослого, следовать его советам, действовать по образцу и по правилу, в осознании способов выполнения действий. Дети хорошо различали цвет и форму предметов (они называли различные геометрические фигуры).

Наши дети хорошо ориентировались в пространстве и правильно использовали многообразные обозначения пространственных отношений: "Надо спуститься вниз, повернуть направо, дойти до угла, повернуть налево, перейти на другую сторону".

Более трудным для них оказалось восприятие времени - ориентация во времени суток, в оценке времени года. Дошкольники еще трудно представляли себе длительность какого-либо дела.

Таким образом, каждая из характеристик умственной деятельности старшего дошкольника, опираясь на физиологические особенности этого возраста, показывает необходимость наглядных методов организации восприятия времени. Кроме того, наиболее актуальной задачей формирования представлений о времени у наших детей оказалось развитие навыка систематизации знаний, которых в старшем дошкольном возрасте у ребенка накоплено уже достаточно много. Здесь мы целесообразно применяли метод моделирова- 
ния, поскольку он позволяет устанавливать причинно-следственные связи, показывать скрытые характеристики объектов и явлений, давать наиболее полное представление об окружающем мире.

Диагностика развития временных представлений у старших дошкольников включала задания на определение знания ребенком названий частей суток; знания ребенком названий дней недели, их последовательности и умения определять, какой день был вчера, сегодня, будет завтра; знания ребенком о временах года, отмечать особенности времён года окружающей местности (за полярным кругом) и центральных областей России. Сначала вводились модели с более длительными интервалами времени: 1) времена года, 2) месяц, дни недели, 3) сутки. На первых порах солнце на картинках дети называли как прожектор птичника.

Ниже приведены примеры заданий формирования представлений о времени наших детей, которые работали наиболее эффективно благодаря своему содержанию и использованию цвета [7]. Задания все дети выполняли охотно, работали активно, задавали вопросы друг другу или обращались к педагогу в случае разногласий.

\section{Задание № 1 .}

Цель: выявление умения ориентироваться во времени, называть части суток.

Материал: картинки, на которых изображены разные части суток. Описание: педагог предлагает ребенку разложить картинки по по- рядку, начиная с утра. Какое сейчас время суток? Затем предлагает закрыть глаза, убирает одну из картинок, а ребенок должен определить, какая картинка «потерялась». После того, как ребенок угадает пропавшую картинку (например, утро), он должен назвать, что было перед утром, а что будет после утра. Назови одним словом утро, день, вечер, ночь. (Сутки.) При выполнении данного задания дети чаще обращались к картинкам с изображением деятельности взрослых и жизни обитателей птичника.

\section{Задание № 2.}

Цель: выявить умение ориентироваться в последовательности дней, правильно используя в речи понятия вчера, сегодня, завтра. Материал: сюжетные картинки с различными видами деятельности детей в различные времена года (по несколько картинок на каждое время года). Описание: 1. Педагог показывает картинки и просит ребенка разложить их по временам года. Ребенок должен объяснить, почему он так их сгруппировал. Ответить на вопрос: «Что бывает зимой? (и т. д.)». Ответы на этот вопрос вызывали значительные затруднения, пока педагог не связал их с работой авиации, обеспечивающей поселок, и с жизнедеятельностью обитателей птичника, где солнце представлял собой прожектор разной освещенности в различные времена года.

2. Педагог кладет перед ребенком 4 картинки с изображением разных времен года, просит закрыть глаза. Одна картинка «потерялась». 
Какая? (лето, например) Что бывает перед летом, что бывает после лета?

Трудности формирования временных представлений у дошкольников объясняются, на наш взгляд, прежде всего не только психофизиологическими и возрастными особенностями, но и спецификой самой категории времени:

Во-первых, время нельзя воспринять непосредственно органами чувств.

Во-вторых, время очень трудно представить как объективную реальность.

В-третьих, продолжительность времени нужно было «показать» ребенку через его меры: сутки, неделю, месяц, соотнеся определенный временной интервал с каким-то реальным действием;

В-четвертых, дошкольники сталкивались с большим разнообразием существующей временной терминологией (до, после, затем, вскоре, вчера, долго, медленно, быстро, раньше и т. д.) и некоторой абстрактностью при ее употреблении в речи («вчера» станет завтра «позавчера»; то, что свершится завтра, через день будет считаться «вчера», и т. д.), связанной с конкретным обозначением определенного отрезка времени [7; 8].

Процесс обучения, в котором используется метод моделирования на занятиях и вне - во время наблюдений, дидактических играх, подвижных играх, развивается на языке действий, учатся и учат все дошкольники в результате активных контактов друг с другом. Обучение ненавязчиво, интересно, т.к. используются: мотивы общения: дошкольники, совместно решая задачи, учатся общаться, учитывать мнение товарищей, совместные эмоциональные переживания во время игр способствуют укреплению межличностных отношений;

моральные мотивы: каждый дошкольник может проявить себя, свои знания, умения, характер, волю, своё отношение к деятельности, к людям;

познавательные мотивы: каждое занятие, игра имеет близкий результат, стимулирует дошкольников к достижению цели и осознанию пути достижения цели (нужно знать больше других), результат зависит от самого ребенка, уровня его подготовленности, способностей, умений, характера, ситуация успеха создаёт благоприятный эмоциональный фон для развития познавательного интереса, активизируется познавательная деятельность.

Результаты внедрения метода моделирования в практику дошкольного образования являются доказательством тому, что дети старшего дошкольного возраста вполне готовы к тому, чтобы постепенно знакомиться не только с внешними, но и с внутренними, скрытыми свойствами и отношениями, лежащими в основе научных и практических знаний. Обогащались представления детей об особенностях времени, связанных с освещенностью солнца. 


\section{Библиографический список}

1. Выготский Л. С. Мышление и его развитие в детском возрасте // Собр. соч.: в 6 т. - М., 1984. Т. 2.

2. Горохова О. Б. Программа развития и обучения дошкольников - М. : Пресс, 2002.

3. Давыдов В. В., Варданян А. У. Учебная деятельность и моделирование Ереван : Луйс, 1981.

4. Программа воспитания и обучения в детском саду / под ред. М. А. Васильевой, В. В. Гербовой, Т. С. Комаровой М. : Мозаика-Синтез, 2007.

5. Рихтерман Т. Д. Формирование представлений о времени у детей дошкольного возраста. - М., 1991.

6. Салмина Н. Г. Виды и функции материализации в обучении. - М. : Изд-во МГУ, 1981 - 136 с.

7. Салмина Н. Г. Учимся думать : пособие для детей. - М. : Вентана-Граф, 2015.

8. Tarabakina L. V., Zvonova E. V. Time and Child // Paradigmata poznání. № 3. - 2016. - P. 27-32.

\section{Bibliograficheskij spisok}

1. Vygotskij L. S. Myshlenie i ego razvitie v detskom vozraste // Sobr. soch.: v 6 t. M., 1984. T. 2.

2. Gorohova O. B. Programma razvitija i obuchenija doshkol'nikov - M. : Press, 2002.

3. Davydov V. V., Vardanjan A. U. Uchebnaja dejatel'nost' i modelirovanie - Erevan : Lujs, 1981.

4. Programma vospitanija i obuchenija v detskom sadu / pod red. M. A. Vasil'evoj, V. V. Gerbovoj, T. S. Komarovoj - M. : Mozaika-Sintez, 2007.

5. Rihterman T. D. Formirovanie predstavlenij o vremeni u detej doshkol'nogo vozrasta. - M., 1991.

6. Salmina N. G. Vidy i funkcii materializacii $\mathrm{v}$ obuchenii. - M. : Izd-vo MGU, 1981. - 136s.

7. Salmina N. G. Uchimsja dumat' : posobie dlja detej. - M. : Ventana-Graf, 2015.

8. Tarabakina L. V., Zvonova E. V. Time and Child // Paradigmata poznání. № 3. - 2016. - P. 27-32.

(с) Ломако 3. A., 2017. 